\title{
A Cohort Comparison Study Evaluating the Role of Protective Foot-wear in Intensive Care Unit
}

\author{
Gitali Bhagawati1,2*, Ashutosh Bhardwaj ${ }^{2,3}$, Sarita Rani Jaiswal ${ }^{2,4}$, Rekha \\ Saji Kumar ${ }^{1}$, Sukhwinder Singh Paul ${ }^{2}$, Sanjeev Prajapati ${ }^{2}$, Arnav \\ Bhagawati $^{5}$ and Suparno Chakrabarti ${ }^{2,4}$ \\ ${ }^{1}$ Department of Microbiology, Dharamshila Narayana Superspeciality Hospital and \\ Research Centre, New Delhi, India \\ ${ }^{2}$ Hospital Infection Control Team, Dharamshila Narayana Superspeciality Hospital and \\ Research Centre, New Delhi, India \\ ${ }^{3}$ Critical Care Medicine, Dharamshila Narayana Superspeciality Hospital and Research \\ Centre, New Delhi, India \\ ${ }^{4}$ Department of Blood and Marrow Transplantation, Dharamshila Narayana \\ Superspeciality Hospital and Research Centre, New Delhi, India. \\ ${ }^{5}$ Department of Design, Indian Institute of Technology, Bombay, India \\ *Corresponding Author: Gitali Bhagawati, Consultant and Head, Department of \\ Microbiology and Infection Control, Department of Microbiology, Dharmshila \\ Narayana Superspeciality Hospital, Vasundhara Enclave, Delhi, India.
}

\section{Abstract}

Background: Intensive care units (ICUs) of many health care organizations (HCOs) consider protective foot-wear like shoe-cover as a component of infection control practices (ICPs) with an assumption that it can prevent Hospital acquired infections (HAIs) in hospital reducing the floor contamination.

Aim: Aim of this study is to find out the efficacy of protective foot-wear on bacterial floor colonization, different colonizers of ICU air and floor and their association with HAIs.

Methods: The prospective study was carried out in an ICU of a superspeciality hospital in Delhi in two phases; Phase I: with shoe covers and Phase II: without shoe covers. In each phase, 36 air culture and 312 swab cultures were collected from particular sites in ICU in morning and evening hours. Blood agar plates, used for processing samples were incubated for 48 hours.

Findings: In air culture, the total colony count was found to be $551 \mathrm{CFU} / \mathrm{mt}^{3}$ in Phase I while it was $723 \mathrm{CFU} / \mathrm{mt}^{3}$ in Phase II (p value $>0.05$ ). In swab cultures, total colony count was $4522 \mathrm{CFU}$ in Phase I while that $4829 \mathrm{CFU}$ in Phase II ( $p$ value $>0.05$ ). In both air culture and swab culture, Methicillin Resistant Coagulase negative Staphylococcus (CoNS) was the predominating organism, followed by Methicillin Sensitive CoNS.

Conclusion: This study shows that there is no statistically significant difference on wearing or not wearing protective foot-wear. In contrast, shoe cover wearing activity can contaminate the hands in which there is more risk of spreading environmental contaminants to the patients if hand hygiene not adequately practiced.

Keywords: Intensive Care Unit; Health Care Organizations; Infection Control Practices; Hospital Acquired Infections; Protective Footwear; Shoe-cover

Citation: Gitali Bhagawati., et al. "A Cohort Comparison Study Evaluating the Role of Protective Foot-wear in Intensive Care Unit". Acta Scientific Microbiology 4.4 (2021): 33-38. 


\section{Abbreviations}

ICU: Intensive Care Unit; HCOs: Health Care Organizations; ICPs: Infection Control Practices; HAIs: Hospital Acquired Infections; PFW: Protective Foot-wear; SC: Shoe-cover; CoNS: Coagulase Negative Staphylococcus; HH: Hand Hygiene; CFU/mt ${ }^{3}$ : Colony Forming Units/metre ${ }^{3}$ (CFU/mt ${ }^{3}$ ), LPCB: Lactophenol Cotton Blue; ATCC: American Type Culture Collection; MRCoNS: Methicillin Resistant Coagulase Negative Staphylococcus; MRSA: Methicillin Resistant Staphylococcus aureus.

\section{Introduction}

Patients admitted in intensive care unit (ICU) are more susceptible to Hospital acquired infections (HAIs) because this group of patients comprises of mostly elderly, immune-compromised with reduced host defense mechanisms. Moreover, they are on many invasive devices like ventilators, central lines, urinary catheters etc. Infection control practices (ICPs) are not up to the mark in ICUs in many health care organizations (HCOs) due to heavy work-load, unnecessary trafficking, frequent change of staff/newly joined staff, non- availability of hand hygiene $(\mathrm{HH})$ products/facilities etc. Unawareness or lack of attitude towards ICPs is another important factor. The overall HAI rate was found to be $45 \%$ in the largest European Prevalence of Infection in Intensive Care (EPIC) study I (1992), out of which $21 \%$ were acquired in the ICU [1]. As per World Health Organization (WHO), out of 100 patients admitted in hospital at a given time, the rate of HAIs is approximately $7 \%$ and $10 \%$ in developed and developing countries respectively. In high-income countries, approximately $30 \%$ of patients in ICU are affected by at least one HAI while this rate is 2 to 3 fold higher in low- and middle-income countries [2]. In some developing countries, the frequency of infections associated with the use of central lines and ventilators and other invasive devices can be up to 19 times higher than those reported from Germany and the USA [2].

One of the important components of ICPs and standard precautions refers to Personal protective equipment (PPE) which comprises of protective clothing, helmets, gloves, face shields, goggles, facemasks and/or respirators or other equipment $[3,4]$. The PPE provides a physical barrier between micro-organisms and the wearer giving protection by helping to prevent microorganisms from contaminating hands, eyes, clothing, hair and shoes; this fur- ther prevents transmission of germs from the wearer to other patients and staff [5]. However, PPE should be according to mode of transmission of diseases and risk of exposure. Use of PFW before entering into the ICUs is considered as ICP in many HCOs with the assumption that floor contamination can cause HAIs [6]. There are many studies to evaluate the importance of protective foot-wear (PFW) in critical care areas; some studies were in favor of PFW [7] while some others found it irrelevant with respect to the HAIs [8$12]$ in patients admitted in critical care areas.

We did this study with the aim to know the actual relevance of SC as PFW before entering into the ICU. A comparative analysis was carried out different bacterial floor colonization, different colonizers of ICU in air and floor, difference in morning and evening colony counts and their association with mortality rate of ICU.

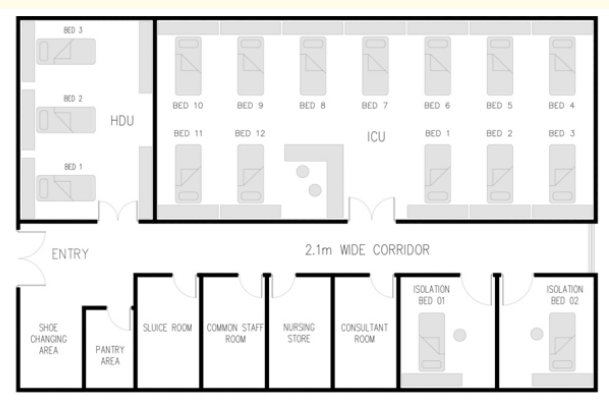

SCHEMATC LAYOUT SCME-175

Figure 1: Schematic layout of Intensive Care Unit showing positions of beds and shoe changing area.

\section{Materials and Methods}

Study design

The prospective study was carried out in an ICU of a 200 bedded tertiary care hospital, India. The study was divided into two phases of one month each, Phase I: with use of PFW in the form of shoecover (SC) and Phase II: without use of PFW.

Air sampling was done by Air sampling system by Himedia (LA637). Air sampling was done thrice in a week after period of 
afternoon attendants' visiting hours; at 5 p.m. In the 17 bedded ICU, 3 different sites were allocated for air sampling: near Bed no. 4, Bed no. 7 and Bed no. 10 [Figure 1]. Single blood agar plate was used to collect the air sample from each dedicated site. A total 36 blood agar plates were used for air sampling in each phase of the study. Samples were collected wearing PPE with PFW in Phase 1 while without PFW in Phase 2.

Similarly floor swabs were collected for culture from six particular areas of ICU: a) shoe cover exchange area b) ICU door handle c) floor area near entrance d) hand-washing area e) floor area near 2 nd bed side and f) floor area near $10^{\text {th }}$ bedside [Figure 1]. A space of $10 \mathrm{~cm} \mathrm{X} 10 \mathrm{~cm}$ was selected for each dedicated area for sample collection. Floor swab samples were taken twice in a day after the period of attendants' visiting hours: at $12 \mathrm{pm}$ and at $5 \mathrm{pm}$. Samples were taken after wearing PPE, including PFW in Phase 1 while without PFW in Phase 2. The swabs were taken out from the tubes, rubbed and rolled several times on the floor to collect the sample. After sample collection, it was immediately sent and processed in the laboratory. A total 312 floor swabs were collected in each phase and processed on blood agar plates.

\section{Microbiological testing}

Blood agar plates were incubated for 24 hours. In case of no growth, plates were re-incubated for further 48 hours. In air culture, number of colonies were counted and expressed as colony forming units/metre ${ }^{3}$ (cfu/mt $\mathrm{mt}^{3}$ ) and from swabs as cfu [13]. Gram stain, Lactophenol cotton blue (LPCB), motility tests, standard biochemical tests were used to identify the bacteria and fungus. Sub-cultures were done on MacConkey agar plates for further identification of Gram negative isolates. Gram negative isolates, Coagulase positive Staphylococcus and budding yeast cells were further identified by automated method (Vitek 2 compact system). Staphylococcus spp. was screened for methicillin sensitivity by cefoxitin $(30 \mu \mathrm{g})$ discs; Methicillin sensitive and methicillin resistant among Staphylococcus spp. was detected as per CLSI guideline, 2018 [14]. Control strains used were: American type culture collection (ATCC) Staphylococcus aureus 25923 and ATCC Escherichia coli 25922

\section{Statistical analysis}

Binary variables were compared between the groups using chisquare test. The outcome was determined to be significantly different if the observed $P$ value was $<0.05$. All analyses were performed using statistical software SPSS Statistics Version 21 (Armonk, USA).

\section{Results and Discussion}

\section{Results}

The study was carried out in an ICU and the samples collected for the study were processed in Department of Microbiology in a tertiary care hospital, India. This comparative analysis was done in two phases, Phase I: with PFW (shoe cover) and Phase II: without PFW. In each phase, 36 air culture plates were used for air sampling in ICU. Similarly, 312 swabs were used for culture in each phase.

In air culture, the total colony count was found to be $551 \mathrm{cfu} /$ $\mathrm{mt}^{3}$ in Phase I while it was $723 \mathrm{cfu} / \mathrm{mt}^{3}$ in Phase II. In swab cultures, total colony count was $4522 \mathrm{cfu}$ in Phase I while that $4829 \mathrm{cfu}$ in Phase II (Table 1)

\begin{tabular}{|c|c|c|}
\hline $\begin{array}{c}\text { Type of } \\
\text { culture } \\
\text { Phase }\end{array}$ & $\begin{array}{c}\text { Air Culture } \mathbf{( N = 3 6 )} \\
\text { colony count } \mathbf{( c f u /} \\
\mathbf{m t}^{\mathbf{3}} \mathbf{)}\end{array}$ & $\begin{array}{c}\text { Swab Culture } \\
(\mathbf{N}=\mathbf{3 1 2}) \text { colony } \\
\text { count } \mathbf{( c f u})\end{array}$ \\
\hline Phase I & 551 & 4522 \\
\hline Phase II & 723 & 4829 \\
\hline
\end{tabular}

Table 1: Air culture and Swab culture findings in Phase I and Phase II.

In air culture, Coagulase negative Staphylococcus (CoNS), both methicillin sensitive and methicillin resistant was the predominating organism (Phase I: $470 \mathrm{cfu} / \mathrm{mt}^{3}$, Phase II: $618 \mathrm{cfu} / \mathrm{mt}^{3}$ ) (Table 2).

Statistically significant Methicillin Sensitive Staphylococcus aureus (MSSA) (49 $\mathrm{cfu} / \mathrm{mt}^{3}$ ) was isolated in Phase I while isolation of Methicillin Resistant Staphylococcus aureus (MRSA) (9 cfu/ $\mathrm{mt}^{3}$ ) was statistically significant in Phase II. Other environmental contaminant Pseudomonas alcaligenes $\left(6 \mathrm{cfu} / \mathrm{mt}^{3}\right)$ and Gram positive rods (Diphtheroids, Bacillus spp) were isolated in Phase II of air culture (p value $<0.05$ ) (Table 2 )

\begin{tabular}{|c|c|c|c|c|c|c|c|}
\hline & & Isolates & $\begin{array}{c}\text { Phase I } \\
\left.\text { (N = } 551 \mathrm{cfu} / \mathrm{mt}^{3}\right)\end{array}$ & $\%$ & $\begin{array}{c}\text { Phase II } \\
\left(723 \mathrm{cfu} / \mathrm{mt}^{3}\right)\end{array}$ & $\%$ & p value \\
\hline \multirow[t]{4}{*}{ Gram positive cocci } & \multirow[t]{2}{*}{ CoNS } & MRCoNS & 352 & 63.88 & 451 & 62.38 & \multirow[t]{2}{*}{0.936} \\
\hline & & MSCoNS & 118 & 21.41 & 167 & 23.10 & \\
\hline & \multirow[t]{2}{*}{ Staphylococcus aureus } & MSSA & 49 & 9.00 & 35 & 4.84 & 0.004 \\
\hline & & MRSA & 0 & 0 & 9 & 1.24 & 0.006 \\
\hline Gram negative bacilli & \multicolumn{2}{|c|}{ Pseudomonas alcaligenes } & 0 & 0 & 6 & 0.83 & 0.039 \\
\hline Gram positive bacilli & \multicolumn{2}{|c|}{ Diphtheroids, Bacillus spp } & 23 & 4.17 & 50 & 6.91 & 0.038 \\
\hline Fungus & \multicolumn{2}{|c|}{ Aspergillus spp. } & 9 & 1.63 & 5 & 0.70 & 0.179 \\
\hline
\end{tabular}

Table 2: Isolates of Air Culture in Phase I and Phase II.

Note: MR: Methicillin Resistant, MS: Methicillin sensitive, CoNS: Coagulase negative Staphylococcus. 


\begin{tabular}{|c|c|c|c|c|c|c|c|}
\hline \multirow{3}{*}{ Gram positive cocci } & \multicolumn{2}{|c|}{ Isolates(CFU) } & PhaseI (N = 4522) & \% & PhaseII (N = 4829) & \% & p value \\
\cline { 2 - 7 } & \multirow{2}{*}{ CoNS } & MRCoNS & 2395 & 52.96 & 2734 & 56.61 & 0.0001 \\
\cline { 2 - 7 } & & MSCoNS & 708 & 15.65 & 1115 & 23.09 & \\
\cline { 2 - 8 } & \multirow{2}{*}{$\begin{array}{c}\text { Staphylococcus } \\
\text { aureus }\end{array}$} & MSSA & 927 & 20.49 & 205 & 4.24 & 0.0001 \\
\cline { 2 - 7 } & MRSA & 267 & 5.90 & 100 & 2.07 & 0.0001 \\
\hline \multirow{2}{*}{ Gram negative bacilli } & \multicolumn{2}{|c|}{ Escherichia coli } & 122 & 2.69 & 60 & 1.24 & 0.0001 \\
\cline { 2 - 7 } & \multicolumn{2}{|c|}{ Klebsiellapneumoniae } & 28 & 0.62 & 152 & 3.15 & 0.0001 \\
\cline { 2 - 7 } & \multicolumn{2}{|c|}{ Pseudomonas alcaligenes } & 0 & 0 & 50 & 1.03 & 0.0001 \\
\hline Gram positive bacilli & \multicolumn{2}{|c|}{ Diphtheroids, Bacillus spp } & 46 & 1.02 & 411 & 8.51 & 0.0001 \\
\hline \multirow{2}{*}{ Fungus } & \multicolumn{2}{|c|}{ Aspergillus spp. } & 4 & 0.09 & 2 & 0.04 & 0.4389 \\
\cline { 2 - 7 } & \multicolumn{2}{|c|}{ Candida albicans } & 25 & 0.55 & 0 & 0.0001 \\
\hline
\end{tabular}

Table 3: Isolates of Swab Culture in Phase I and Phase II.

In swab culture also, the predominant organism isolated was CoNS, both methicillin sensitive and methicillin resistant (Phase I: 3103 cfu; Phase II: 3849 cfu); statistically significant in Phase II.

In contrast, isolation of MSSA (Phase I: $927 \mathrm{cfu}$; Phase II: 205 cfu) and MRSA (Phase I: $267 \mathrm{cfu}$; Phase II: $100 \mathrm{cfu}$ ) were statistically significant in Phase I. Other significant organisms ( $\mathrm{p}$ value $<0.05$ ) isolated in Phase I were E.coli and Candida spp.; while that of Phase II were Klebsiella pneumoniae and environmental contaminants Pseudomonas alcaligenes and Gram positive rods (Diphtheroids, Bacillus spp) (p value $<0.05$ ).

On comparing the growths in swabs collected in morning and evening hours, the evening hour collected samples showed more growth than the morning hours except in three sites (hand washing area, between bed no. 02 and 05 and between bed no. 10 1nd 11) in Phase II (Figure 2, Figure 3).

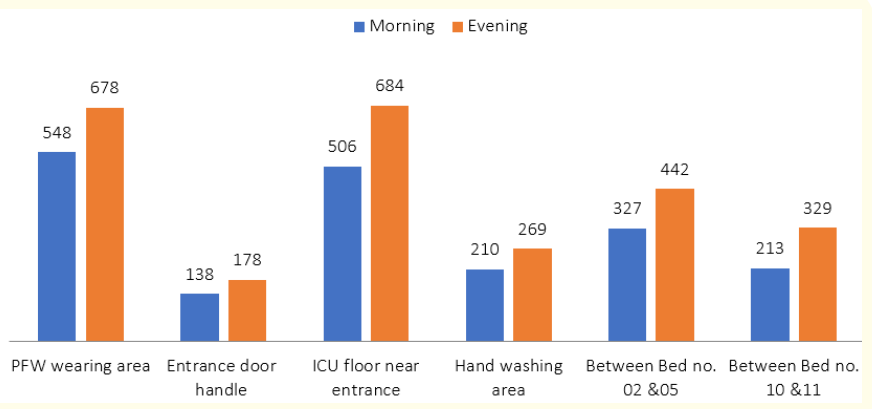

Figure 2: Distribution of growth (cfu) in swab culture in morning and evening hours in Phase I.

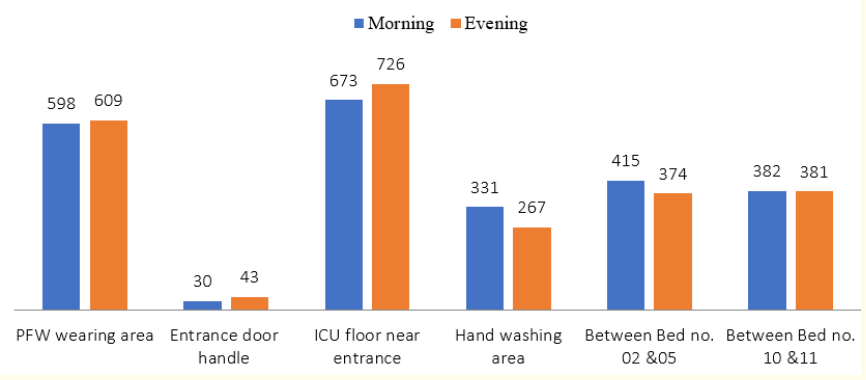

Figure 3: Distribution of growth (cfu) in swab culture in morning and evening hours in Phase II.
Growth in swab samples were statistically significant in Phase I for PFW wearing area and entrance door handle of ICU ( $p$ value $<0.05$ ) while that in Phase II were floor near entrance,hand washing area and between bed no. 10 and 11 (Table 4).

\begin{tabular}{|c|c|c|c|c|c|c|}
\hline $\begin{array}{c}\text { Serial } \\
\text { no. }\end{array}$ & Areas & $\begin{array}{c}\text { Phase I } \\
\text { (N= 4522 } \\
\text { cfu) }\end{array}$ & \% & $\begin{array}{c}\text { Phase } \\
\text { II (N = } \\
\mathbf{4 8 2 9} \mathbf{c f u})\end{array}$ & $\mathbf{\%}$ & p value \\
\hline 1 & $\begin{array}{c}\text { PFW wearing } \\
\text { area }\end{array}$ & 1226 & 27.11 & 1207 & 24.99 & 0.020 \\
\hline 2 & $\begin{array}{c}\text { Entrance door } \\
\text { handle }\end{array}$ & 316 & 6.98 & 73 & 1.51 & 0.0001 \\
\hline 3 & $\begin{array}{c}\text { Floor near } \\
\text { entrance }\end{array}$ & 1190 & 26.31 & 1399 & 28.97 & 0.004 \\
\hline 4 & $\begin{array}{c}\text { Hand washing } \\
\text { area }\end{array}$ & 479 & 10.59 & 598 & 12.38 & 0.013 \\
\hline 5 & $\begin{array}{c}\text { Between Bed } \\
\text { no. 02 and 05 }\end{array}$ & 769 & 17 & 789 & 16.34 & 0.389 \\
\hline 6 & $\begin{array}{c}\text { Between Bed } \\
\text { no. } 10 \text { and } 11\end{array}$ & 542 & 11.98 & 763 & 15.8 & 0.0001 \\
\hline
\end{tabular}

Table 4: A comparative analysis of area wise distribution of growth in swab cultures in ICU (no. of cfu and \%).

On comparing the Hospital mortality rate in ICU with the growth in air culture and swab culture, statistically insignificant relation was obtained ( $\mathrm{p}$ value $>0.05$ ) (Table 5).

\begin{tabular}{|c|c|c|c|}
\hline $\begin{array}{c}\text { Phase } \\
\text { (Months) }\end{array}$ & $\begin{array}{c}\text { Growth in Air } \\
\text { Culture (cfu/mt }\end{array}$ & $\begin{array}{c}\text { Growth in Swab } \\
\text { Culture(cfu) }\end{array}$ & $\begin{array}{c}\text { Overall } \\
\text { Mortality Rate } \\
\text { in ICU (\%) }\end{array}$ \\
\hline Phase I & 551 & 4522 & 13.54 \\
\hline Phase II & 723 & 4829 & 12.12 \\
\hline
\end{tabular}

Table 5: Mortality rate in ICU in Phase I and Phase II.

\section{Discussion}

Studies reveal that $15 \%$ of airborne CFUs get dispersed in air from floor contamination [15]. In our study, CoNS is the most common isolate in both Phase I and Phase II of swab culture and air culture which is the major commensal flora of human skin and mucosa that comprises of greater than $90 \%$ of the aerobic resident 
flora [16]. Healthy skin daily disseminates approximately $10^{7}$ particles into the air, out of which $10 \%$ squames contain viable bacteria [17]. Cleaning and disinfection decreases microbial colony count by $80 \%$ and $95-99 \%$ respectively which sustains for only few hours depending upon trafficking in ICU. Type of mopping is also important factor associated with it. Humidified mopping and dry mopping reduces colony count by $75 \%$ and $55 \%$ respectively $[6,18]$.The colony count is inversely proportional to the duration of cleaning and disinfection. This explains the possibility of different colony counts in morning and evening hours; although the difference was not statistically significant (Figure 1 and Figure 2).

The predominant organism that comprises of $99 \%$ of dry ward floor consists of Staphylococcus epidermidis and other CoNS, diphtheroids and bacillus species [6,19]. In our study also, CoNS was the predominating organism in both air and swab culture, while Gram positive rods (Diphtheroides and Bacillus spp.) were found to be significantly higher in swab cultures in Phase II. Various studies done in critical care areas also go with the similar findings $[8,12,15,19]$ while few studies shown growth of MRSA and Fungus as the predominating microorganism in floor swabs [6]. In our study, isolation of MRSA was statistically significant irrespective of use of shoe-cover in ICU.

The predominating organisms found by E.O. Nwankwo et. al. from operation theatre (OT) foot- wear comprised of Micrococcus 43 (22\%), Bacillus circulans 28 (14.36\%) Staphylococcus epidermidis 27 (13.85\%). Potential pathogenic/opprtunistic microorganism comprised of Staphylococcus aureus 5 (2.56\%), Klebsiella spp. 5(2.56\%), E. coli $13(6.66 \%)$ and Pseudomonas putida 5 (2.56\%) [20].

CoNs, coliforms, Bacillus and diphtheroides were the predominant isolates from OT foot-wear as per findings of R. Amirfeyz [15].

Here, we had found that the shoe changing area had grown more number of colonies in Phase I in comparison to Phase II, while the ICU door handle had grown less numbers of colonies in Phase I in comparison to Phase II (Table 4). The activities of wearing shoe covers usually contaminate the hands of HCWs and visitors which further contaminate the door handles of ICU, a highly touched area. Increasing rate of bacterial contamination in footwear changing areas and its association with hand contamination was found by some other authors as well $[8,13,14]$.

Another study reveals that contamination of a floor while walking was about 16 times higher than contamination of the floor due to sedimentation only; which finally showed no significant difference in floor contamination with the use of different foot-wears like ordinary shoes, clean shoes, shoe covers etc. [9].

Our study is in contentious with some other studies demonstrating there is no statistically significant difference in floor contamination with the use or non-use of over shoes, use of different types of shoes (ordinary shoes, clean shoes, shoe covers) for outside and inside critical areas [8-12]. However some studies found benefit [7]. Study done in Scotland for operation theatre, Hospital Infection Society Working Party on Infection Control recommended that the use of shoe covers/overshoes should cease [21,22]; similarly shoe covers/overshoes was not recommended by the Association of Anaesthetists of Great Britain and Ireland [21,23].
If HH is not adequate in ICU, bacteria from hands of HCWs can spread from shoe cover to door handle of ICU then to the patient which can cause HAIs. Hence, HH is the primary infection prevention practice which should be stringently followed in all health care areas. In our set up, we strictly follow hand hygiene policy; the compliance rate of it varies from $70-80 \%$ in ICU.

\section{Conclusion}

This study shows that there is no statistically significant difference wearing or not wearing PFW in ICU. Rather, SC wearing activity can contaminate the hands which have more risk of spreading environmental contaminants to the patients if $\mathrm{HH}$ activity is skipped. Another important finding is that wearing SC do not make the environment microbe free. Although, MRSA, E.coli are more in SC wearing phase while Klebsiella pneumoniae, Pseudomonas alcaligenes are more in SC non-wearing phase. This shows that environment cannot be free of microbes despite of wearing shoe-covers. Moreover, shoe covers which can pollute the environment if not properly disposed of. We should rather focus on stringent HH practices and cleaning and disinfection policy of the ICU to make it free of harmful pathogens.

Using our findings, we decided to eliminate PFW in the form of SC in our ICU and focused on other ICPs.

\section{Acknowledgements}

Our acknowledgement goes to Mr. Anuj Gupta, CEO Dharamshila Narayana Superspeciality Hospital, Delhi for his support to conduct the study in our institute.

\section{Conflict of Interest}

Declare if any financial interest or any conflict of interest exists.

\section{Bibliography}

1. Spencer RC. "Epidemiology of infection in ICUs". Intensive Care Medicine 20 (1994): 2-6.

2. Health care-associated infections FACT SHEET. World Health Organisation. Patient safety, A World alliance for Safer Health care, save Lives, Clean Your hands.

3. Standard precautions in Health care. World Health Organization, CH-1211 Geneva-27 Switzerland (2007).

4. Mangram AJ., et al. "Guideline for prevention of surgical site infection. Hospital Infection Control Practices Advisory Committee". Infection Control Hospital Epidemiology 20.4 (1999): 279-280.

5. Cleanliness Champions: Promoting the Prevention and Control of Infection UNIT4 Personal Protective Equipment (PPE) NHS Education for Scotland | Programme workbook for open and distance learning.

6. A Gupta., et al. "Impact of Protective Footwear on Floor and Air Contamination of Intensive Care Units". Medical Journal of Armed Forces India. 63.4 (2007): 334-336.

7. G Copp., et al. "Footwear practices and operating room contamination". Nursing Research 36.6 (1987): 366-369. 
8. H Humphreys., et al. "Theatre over-shoes do not reduce operating theatre floor bacterial counts" Journal of Hospital Infection 17.2 (1991): 117-123.

9. NC Weightman., et al. "Protective over-shoes are unnecessary in a day surgery unit". Journal of Hospital Infection 28.1 (1994): 1-3.

10. AM Santos., et al. "Evidence of control and prevention of surgical site infection by shoe covers and private shoes: a systematic literature review". Revista Latino Americana de Enfermagem 13. 1 (2005): 86-92.

11. Z Ali., et al. "To determine the effect of wearing shoe covers by medical staff and visitors on infection rates, mortality and length of stay in Intensive Care Unit". Pakistan Journal of Medical Sciences 30.2 (2014): 272-275.

12. JG Collee., et al. "Tests for the identification of bacteria". Mackie and MaCartney Practical Medical Microbiology 14 (2008): 131-149.

13. Performance Standards for antimicrobial susceptibility Testing. Clinical and Laboratory Standards Institute. $28^{\text {th }}$ Edition (2018).

14. R Amirfeyz., et al. "Theatre Shoes- A Link in the Common Pathway of Postoperative Wound Infection?". Annals of the Royal College of Surgeons England 89.6 (2007): 605-608.

15. EA Grice., et al. "The skin microbiome". Nature Reviews Microbiology 9.4 (2011): 244-253.

16. E Larson. "Hygiene of the Skin: When Is Clean Too Clean?" Emerging Infectious Diseases. 4th Decennial International Conference on Nosocomial and Healthcare-Associated Infections 7.2 (2001).

17. BM Andersen., et al. "Floor cleaning methods of patients' room: Effect on bacteria, dirt and particles". Tidsskr Nor Laegeforen 117 (1997): 838-841
18. WC Noble., et al. "Studies on the dispersal of Staphylococci". Journal of Clinical Pathology 18 (1965): 18-20.

19. GAJ Ayliffe., et al. "Hospital-acquired Infection; Principles and Prevention". 2 (1990): 124.

20. I Nagai et al. "Studies on the mode of bacterial contamination of an operating theatre corridor floor". Journal of Hospital Infection 5 (1984): 50-57.

21. Standard Infection Control Precautions Literature Review: Personal Protective Equipment (PPE) Footwear Health Protection Scotland (HPS). National Services Scotland. Version 2.0 August (2015).

22. K Woodhead., et al. "Behaviours and rituals in the operating theatre. A report from the Hospital Infection Society Working Party on Infection Control in Operating Theatres". Journal of Hospital Infection 51.4 (2002): 241-255.

23. Association of Anaesthetists of Great Britain and Ireland. "Infection control in anaesthesia". Anaesthesia 63.9 (2008): 1027-1036.

\section{Assets from publication with us}

- Prompt Acknowledgement after receiving the article

- Thorough Double blinded peer review

- Rapid Publication

- Issue of Publication Certificate

- High visibility of your Published work

Website: https://www.actascientific.com/

Submit Article: https://www.actascientific.com/submission.php Email us: editor@actascientific.com

Contact us: +919182824667 